\title{
Bacteria Exhibiting Antimicrobial Activities; Screening for Antibiotics and the Associated Genetic Studies
}

\author{
Muaz Mutaz Al-Ajlani and Shahida Hasnain*
}

Department of Microbiology and Molecular Genetics, University of the Punjab, Quaid-e-Azam Campus, Lahore, Pakistan

\begin{abstract}
A total of 118 bacterial strains were isolated from six different soil samples from different parts of Pakistan. 50 out of these strains exhibited antagonistic activities against at least two or more strain from a panel of pathogenic and nonpathogenic microorganisms. Tested strains included three sets; environmental, laboratory and multidrug resistant clinical isolates. Twelve strains exhibited diverse spectrum of activity are focus of further work. The bacterial species identified include Bacillus subtilis, B. amyloliquefaciens, B. cereus, and B. licheniformis. Identified strains showed interesting biological activities e.g. inhibiting the growth of clinical isolates (Klebsilla species), strong antifungal and anti-algal activities and high toxicity against Artemia sp., while their TLC and HPLC profile showed an impressive chemical diversity. All the strains were able to produce number of peptides (surfactins, iturins, fengycins, subtilin and subtilosin) in different combinations. Presence of $s b o X$ gene was not correlated with subtilosin production, however, subtilosin and sboX were confirmed in Bacillus amyloliquefaciens for the first time.
\end{abstract}

Keywords: Bacillus, Antimicrobial activities, Antibiotics, sboX gene.

\section{INTRODUCTION}

Screening for new antibiotics from natural sources is becoming increasingly important for the pharmaceutical industry [1] as pathogenic bacteria are quickly becoming resistant to commonly used therapeutic agents [2]. Secondary metabolites from microorganisms have a diverse chemical structure and biological activities and are produced only by some species of a genus Bacillus [3]. Some examples of these antibiotics used in medical treatments are bacitracin, Gramycidin S, polymyxin, and tyrotricidin [4] produced by different Bacillus spp. The antibiotics produced by Bacillus are more effective against Gram-positive organisms; however, compounds such as polymyxin, colistin, and circulin exhibit activity against Gram negative organisms [5]. Lipopeptides produced by Bacillus also demonstrate anti-fungal [6], anti-viral [7], anti-ameobocytic [8] and anti-mycoplasma [9] activities. Lipopeptide antibiotics are members of a particular antibiotic class formed by surfactin [10], iturin [11], fengycin [12] and plipastatin [13] families. The chemical and physical diversity of peptide antibiotics makes them ideal candidates not only for therapeutic applications but also in other areas, especially the agri-food industry [14].

Subtilosin A is one of many antibiotics produced by Bacillus strains [15-17]. The spectrum of activity was investigated and proved antagonism against a wide range of bacteria including Gram-positive and Gram-negative bacteria and both aerobes and anaerobes [18]. The production of mature subtilosin is based on the expression of the sbo-alb

*Address correspondence to this author at the Department of Microbiology and Molecular Genetics, University of the Punjab, Quaid-e-Azam Campus, Lahore, Pakistan; Tel: +92-42-99238530; Fax +92-42-99230481:

E-mail: shahida@mmg.pu.edu.pk, genetic@brain.net.pk gene cluster encompassing the subtilosin structural gene $s b o$ and genes involved in posttranslational modification, processing of presubtilosin and immunity $[17,19]$.

This study attempts at investigating the antimicrobial activities of Bacillus species isolated from 6 different soil samples. The selected strains were identified, their activity spectra were determined against other strains. Further peptide secondary metabolites and presence of $s b o$ gene in antimicrobial exhibiting Bacillus strains is being reported.

\section{METHODS}

\section{Screening and Isolation}

Six different soil samples were taken from different localities of Lahore in Pakistan. Each $1 \mathrm{~g}$ of the sample was suspended in $9 \mathrm{ml}$ sterile distilled water and shaken vigorously for $2 \mathrm{~min}$. The samples were heated at $80^{\circ} \mathrm{C}$ for $40 \mathrm{~min}$ in a water bath. The soil suspension was serially diluted in sterile distilled water and the dilution from $10^{-6}$ and $10^{-7}$ were plated on overlaid Nutrient agar $0.8 \%$ [20] with seeded test organisms and incubated at $37^{\circ} \mathrm{C}$ for 12 to 24 hours, to screen for antagonistic bacteria. Colonies giving zone of inhibition were isolated and re-streaked over a fresh media plate. Eventually selected candidate were collected from the reservoir plate and rechecked for their activity.

\section{Media and Culture Condition}

Growth was on Nutrient broth, Nutrient agar and minimal salt medium [21]. In all cases, pre-inoculum was prepared by suspending in $10 \mathrm{ml}$ deionized water colonies taken from minimal salt agar. The suspensions were adjusted to $5 \times$ $10^{12}$ cells per ml. Growth temperature and $\mathrm{pH}$ values were maintained at $37^{\circ} \mathrm{C}$ and $7 \pm 0.5$, respectively. Fermentation was carried out for 24 or 48 hours in $250 \mathrm{ml}$ conical flasks containing $50 \pm 5 \mathrm{~mL}$ broth on an orbital shaker operating at $120 \mathrm{rev} / \mathrm{min}$. 
Table 1. Samples Collected for the Isolation of Antimicrobial Exhibiting Bacteria (AEB) and Some Physico-Chemical and Microbiological Properties

\begin{tabular}{|c|c|c|c|c|}
\hline Sample & Source and Characteristics & $\begin{array}{l}\text { No. of Bacterial } \\
\text { Isolates }\end{array}$ & $\begin{array}{c}\text { No. of Antagonistic } \\
\text { Isolates }\end{array}$ & $\begin{array}{l}\text { Designation of } \\
\text { selected strains }\end{array}$ \\
\hline A & $\begin{array}{l}\text { Punjab, Lahore, Canal bank, P.U. Campus area. 2003. Soil: light brown, } \\
\text { loamy, partly humid with root remnants and alkaline ( } \mathrm{pH} \mathrm{7.8)}\end{array}$ & 21 & 7 & A15 \\
\hline B & $\begin{array}{l}\text { Punjab, Lahore, Canal bank, P.U. Campus area. 2004. Soil: brown, } \\
\text { loamy, humid with root \& leave remnants and alkaline (pH 7.8) }\end{array}$ & 34 & 15 & $\begin{array}{l}\mathrm{B} 3, \mathrm{~B} 4, \mathrm{~B} 5, \mathrm{~B} 7, \mathrm{~B} 8, \\
\mathrm{~B} 29, \mathrm{~B} 30, \mathrm{~B} 34, \mathrm{~B} 71\end{array}$ \\
\hline $\mathrm{D}$ & $\begin{array}{l}\text { Punjab, Lahore, Canal bank, P.U. Campus area. 2003. Soil: brown, } \\
\text { sandy, dry with some rocks and alkaline (pH 7.9) }\end{array}$ & 29 & 12 & \\
\hline $\mathrm{E}$ & $\begin{array}{l}\text { Punjab, Lahore, Canal bank, P.U. Campus area. 2003. Soil: light brown, } \\
\text { loamy, partly humid with root remnants and alkaline }(\mathrm{pH} 8.5)\end{array}$ & 28 & 13 & \\
\hline
\end{tabular}

\section{Identification and 16S r DNA Analysis}

In the identification of isolated bacteria species, standard taxonomic descriptions were used [22]. Genomic DNA was extracted from overnight incubated bacterial cultures in Luria Bertani LB-broth [20] at $37{ }^{\circ} \mathrm{C}$ with $120 \mathrm{rpm}$. The extraction was carried out by using gene extraction kit (Biorad, UK). PCR amplification of 16S rDNA was performed successfully following the method described by Hasnain and Thomas [23]. To 0.5-0.1 ng of chromosomal template DNA, $0.25 \mu \mathrm{M}$ each primer, $200 \mu \mathrm{M}$ deoxynucleoside triphosphate and 1 unit of Taq polymerase were added. Solution was heated to $94^{\circ} \mathrm{C}$ for $5 \mathrm{~min}$ and passed through 29 cycles as follows: denaturation for $20 \mathrm{~s}$ at $94^{\circ} \mathrm{C}$, primer annealation for $20 \mathrm{~s}$ at $50^{\circ} \mathrm{C}$ and extension at $72{ }^{\circ} \mathrm{C}$ for $2 \mathrm{~min}$. Final extension was at $72{ }^{\circ} \mathrm{C}$ for $5 \mathrm{~min}$. The product was purified using Aqua pure extraction kit (Fermantas, UK) and sequenced using $27 \mathrm{f}$ and $1522 \mathrm{r}$ as forward and reverse primer respectively [24].

\section{Spectrum of Activity}

Spectra evaluation was performed by stabbing method [25] for all selected isolates starting from the indigenous strains found in the same sample (Cross sensitivity) and 13 different Laboratory collected strains (Escherichia coli C600, Escherichia coli DH5a1, Bacillus subtilis PY49, Bacillus subtilis 92, Bacillus subtilis 29, Bacillus fusiformis 5, Bacillus subtilis 1A309, Bacillus subtilis 5A29, Bacillus subtilis 3A22, Bacillus subtilis 1G1, Bacillus subtilis 22A1, Bacillus subtilis 1A321, Bacillus subtilis 1A106), 8 clinical isolates of Klebsiella spp. (collected from Children Hospital, Lahore, Pakistan), 22 isolates of Staphylococcus aureus, 18 isolates of Streptococcus pyogenes, and 85 unidentified clinical isolates (Social Security Hospital, Lahore, Pakistan).

\section{Antimicrobial Substances (AMS) Assay}

Culture supernatants containing the antibiotic were assayed for activity using an agar-well diffusion assay [26]. $50 \mu \mathrm{L}$ antibiotic sample was transferred into the well.
Sample was allowed to diffuse into the agar, the plate was then inverted and incubated at $37{ }^{\circ} \mathrm{C}$ until a lawn of the indicator bacteria appeared on the plate (approximately 8-10 hrs).

\section{Chemical Screening}

Chemical screening was performed in parallel to biological screening over crude extracts of antimicrobial exhibiting bacteria (AEB). Preparation of crude extract: broths of grown bacteria with optimum conditions and broth medium were freeze dried and extracted with ethyl acetate three times. Filtered extract was concentrated under vacuum and dried under steam of continuous air.

\section{Thin Layer Chromatography}

Crude extracts were run on TLC 30 (F 250) and substances were visualized by UV absorption at 250 and 235 $\mu \mathrm{m}$, chromogenic reaction with spray reagents e.g. anisaldehyde and Ehrlich. Active bands were visualized using bioautography method in which suspensions of indicator organisms in agar or broth are overlaid on chromatograms to detect bioactive spots/ areas.

\section{HPLC-MS}

The application of hyphenated techniques like highperformance liquid chromatography (HPLC) coupled to electrospray ionization tandem mass spectrometry (ESI-MS) has influenced much our approach to explore natural products. HPLC-MS is a sensitive and powerful tool for natural product chemistry permitting a fast screening of the metabolic profiles with a minimum amount of material. The crude extract was dissolved in a HPLC grade methanol injected to a HPLC/MS set up. HPLC was run on a Eurospher C-18 reversed phase column. Every chromatogram HPLC peaks were analyzed directly through ESI-MS to provide the corresponding molecular weights. These results were analyzed with AntiBase [27] and recorded as hits indicating identical or a near match in molecular weights with other known compounds. 


\section{Detection and Sequencing of sbo Genes}

$s b o$ and its flanking region were detected from the environmental Bacillus strain.Genomic DNA was extracted from overnight inoculated bacterial culture in L-broth at $37^{\circ} \mathrm{C}$ with $120 \mathrm{rpm}$. PCR amplification of $\sim 1375$-bp consisted of sbo and flanking region was performed successfully with TS13C (GAATTGACACTATCTAG AGAAATGC CG) and TS14 (ATCCGGTGGTGCGGAATT CGATGA) [16]. The optimum PCR conditions were determined as heating $94^{\circ} \mathrm{C}$ for $5 \mathrm{~min}$ through 30 cycles as follows: denaturation for $30 \mathrm{~s}$ at $94{ }^{\circ} \mathrm{C}$ primer annealation for $30 \mathrm{~s}$ at $59^{\circ} \mathrm{C}$ and extension at $72^{\circ} \mathrm{C}$ for $1.2 \mathrm{~min}$. Final extension was at $72^{\circ} \mathrm{C}$ for $3 \mathrm{~min}$. PCR products were analyzed by $1.5 \%$ agarose gel electrophoresis. The purified PCR products were sequenced by using an ABI Prism dye terminator cycle sequencing ready reaction kit and an $\mathrm{ABI}$ PRISM 377 DNA sequencer (Applied Biosystems, USA). Analyses of DNA sequences were performed by using Prochromas version software (Oxford Molecular, UK).

\section{MALDI-TOF-Mass Spectrometry}

Fractions correlated with surfactin from TLC and Reverse phase HPLC were analyzed using MALDI-TOFMS. $2 \mu \mathrm{L}$ of samples were mixed on the target plate with 2 $\mu \mathrm{L}$ of matrix solution ( $2 \mathrm{mg}$ of alpha-hydroxycinnaminic acid per $\mathrm{ml}$ in acetonitrile-methanol-water, 1:1:1). MALDITOF-MS spectra were recorded by using a 337-nm nitrogen laser for desorption and ionization. The mass spectrometer was operated in the refraction mode at an accelerating voltage of $18 \mathrm{kV}$ with an ion flight path that of $0.7 \mathrm{~m}$. The delay time was 375 ns. Matrix-suppression was also used, and the mass spectra were averaged over 50 to 100 individual laser shots. The laser intensity was set just above the threshold for ion production. External calibration was performed by using the $[\mathrm{M}+\mathrm{H}]+$ signals of renin, adenocorticotropic hormone, insulin oxidized $\mathrm{B}$, and bovine insulin (Sigma-Aldrich Co.). Surfactin isomers were anticipated to have an $\mathrm{m} / \mathrm{z}$ range of $500-1500$. The variance of the $m / z$ of $\pm 0.8 \mathrm{Da}$ was considered acceptable.

\section{RESULTS AND DISCUSSION}

\section{Isolation and Identification}

From six different soil samples a total of 118 morphologically different bacterial strains were isolated among them fifty strains were found to have antimicrobial activities against at least two tested organisms (Table 1). $42.34 \%$ of the strains recovered from all samples could exhibit antimicrobial activities. Selected strains were identified on the basis of 16S rDNA sequence homology compared to their nearest sequence matches. As a result of identification, 12 Bacillus spp. strains were identified as $B$. subtilis, B. amyloliquefaciens and B. licheniformis (Table 2).

\section{Evaluation of Spectrum of Activity}

The spectra for activity of isolated strains were evaluated against indigenous strains; laboratory collected strains, as well as clinical isolates Fig. (1). The lowest activity was exhibited against clinical isolates (19.5\%). 36\% of the strains were active against laboratory collected strains and $67 \%$ were active against environmental isolates. Strains that showed large and clear inhibitory zones against Gram positive or Gram negative test bacterial strains were considered as potential producers of antimicrobial substances (AMS). Twelve out of "118" (10.17\%) bacterial strains were observed to be most active and were selected for further study (Table 2). These strains exhibited a wide spectrum of activity against Gram positive, Gram negative and clinical isolates.

\section{Biological Activity}

The inhibitory activity of each of these 76 strains from 3 soil samples (A, B, C as majority of antimicrobial exhibiting isolates pertain to these samples) was detected against all others strains of same sample in cross sensitivity tests and also against at least 14 indicator strains (Table 3) using stabbing method. Inhibitory activity against endogenous and important pathogenic microbes was observed and marked using symbols; +++ clear and large inhibitory zone $>4 \mathrm{~mm}$,

Table 2. Bacterial Strains and Assigned Homologous Counterparts Based on 16S rDNA Sequence Analysis

\begin{tabular}{|c|c|c|}
\hline Designation & Highest homology counterpart & Accession No. \\
\hline \hline Strain A15 & Bacillus licheniformis strain CICC10093 & AY842874 \\
\hline Strain B 7 & Bacillus subtilis strain 3A25 & DQ400916 \\
\hline Strain B 30 & Bacillus subtilis strain B-FS01 & EF1599459 \\
\hline Strain B29 & Bacillus subtilis strain CGMCC1869 & AY620954 \\
\hline Strain B 34 & Bacillus amyloliquefaciens & AY583216 \\
\hline Strain C6 & Bacillus subtilis strain BS-S3 & EU586791 \\
\hline Strain B 71 & Bacillus sp. G1DM-10 & EU586784 \\
\hline Strain B 3 & Bacillus sp. cp-h61 & EU586785 \\
\hline Strain B 4 & Bacillus sp. & EU586783 \\
\hline Strain B 5 & Bacillus sp. cp-h23 & DQ327713 \\
\hline Strain B 8 & Bacillus sp. & EU686585 \\
\hline Strain B 9 & Bacillus sp. & \\
\hline
\end{tabular}


++ clear zone up to $4 \mathrm{~mm},+$ presence of zone, \pm incomplete zone, - no zone. A total of thirty six out of $76(47.368 \%)$ bacterial isolates showed inhibitory zones on Lauria Bertani agar plates against indicator strains.

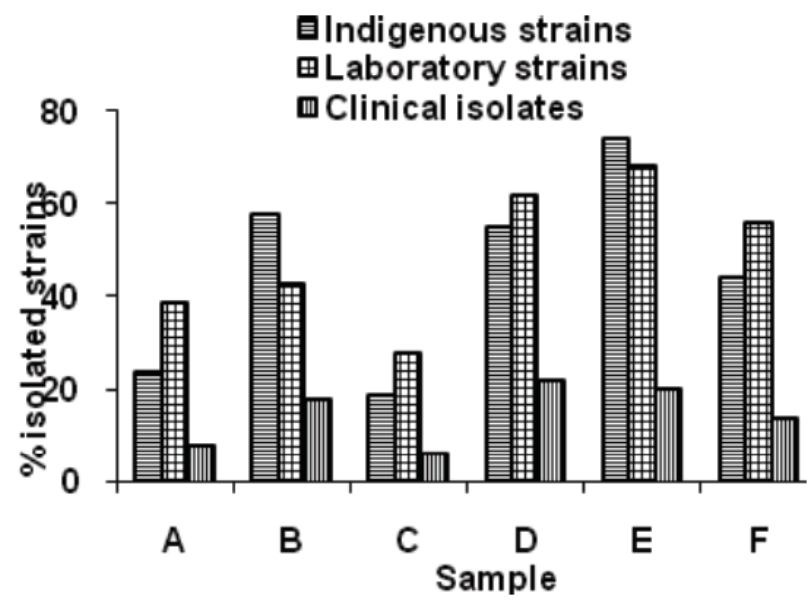

Fig. (1). Antimicrobial activity of bacterial strains isolated from 6 different soil samples against (a) indigenous strains, (b) laboratory collected strains, and (c) clinical isolates.

Each strain that showed large and clear inhibitory zones against gram positive as well as gram negative test bacterial strains was considered as potential producers of antimicrobial substances (AMS). Thirty six out of "76" bacterial strains were observed to be most active and been selected for further study. Twelve out of thirty six strains were observed to be gram positive having potential antimicrobial activity (Table 4). Three strains were showing large +++ inhibitory zones against Bacillus subtilis 5A29. Bacterial strains A15, B3, C6, were showing inhibitory zones ++ against Escherichia coli DH5 $\alpha 1$. Thirteen out of anti-bacterial isolates were observed to be having +++ activity against B8 endogenous bacterial strains. Final selected strains are A 15, B 7, B 30, B 29, B 34, C 6, B 71, B 3, B 4, B 5, B 8, B 9.

Influence of Temperature, $\mathrm{pH}$ and Aeration on the Production of Antimicrobial Substances (AMS)

The influence of temperature, $\mathrm{pH}$ and aeration was observed on the production of antimicrobial substances (AMS) in LB medium Cell free supernatants showing inhibitory activity were obtained when the strains were grown in a range of $\mathrm{pH} 4-10$, temperature $25-45^{\circ} \mathrm{C}$ and in still or shaking cultures. However, the maximum antimicrobial activity was observed when strains were cultivated as shaking cultures, $\mathrm{pH}-7.0$ and temperature $30^{\circ} \mathrm{C}$.

\section{Isolation and Purification of Active Substances}

Three different isolation methods were employed for six strains. For strains B 8 and B 5 liquid-liquid extraction in combination with TLC was used. For strains B 9 and B 7 ammonium sulfate precipitation followed by gel filtration

Table 3. Selected Antibiotic Producing Strains and their Spectrum of Activity, (++) Clear Zone >10mm, (+) Clear Zone up to 5mm

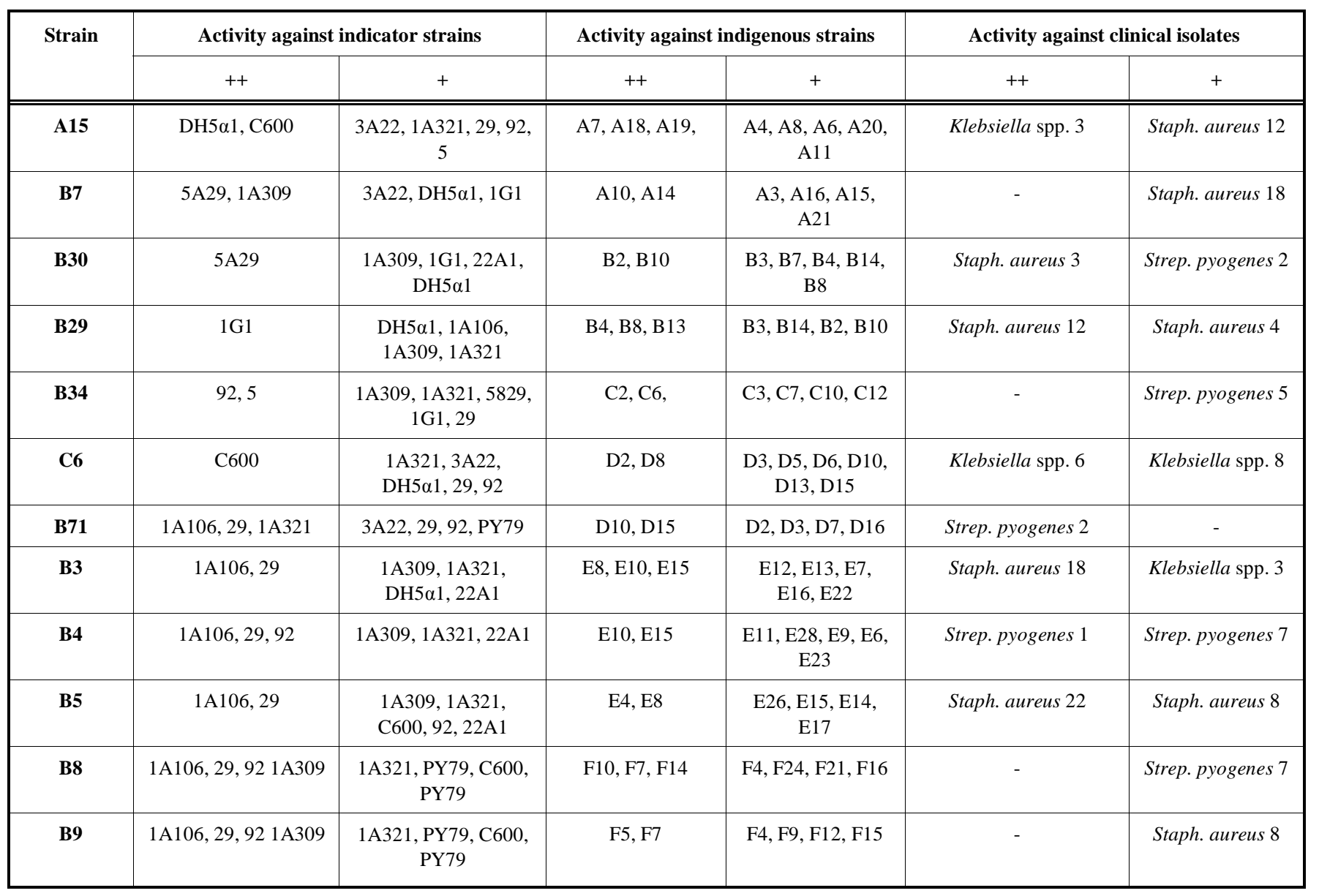


Table 4. Factors Affecting Antimicrobial Production

\begin{tabular}{|c|c|c|c|c|c|c|c|c|}
\hline \multirow{2}{*}{ Strain No. } & \multicolumn{3}{|c|}{$\mathbf{p H}$} & \multicolumn{3}{|c|}{ Temperature } & \multicolumn{2}{|c|}{ Aeration } \\
\hline & \multicolumn{8}{|c|}{ Zone of Inhibition $\mathrm{ZOI}_{(\mathrm{mm})}$} \\
\hline A 15 & 17 & 37 & 10 & 35 & 35 & 20 & 40 & 35 \\
\hline B 7 & 10 & 33 & 0 & 37 & 32 & 21 & 34 & 32 \\
\hline B 29 & 0 & 18.5 & 12.5 & 15 & 20.5 & 13 & 15 & 20.5 \\
\hline B 34 & 12.5 & 34 & 14 & 36 & 36 & 20.5 & 36 & 36 \\
\hline C 6 & 0 & 33 & 36 & 32 & 32 & 21 & 35 & 32 \\
\hline B 71 & 13.5 & 34 & 11 & 34 & 36 & 12.5 & 38.5 & 36 \\
\hline B 5 & 15.5 & 18.5 & 14.5 & 24 & 16.5 & 12 & 24 & 16.5 \\
\hline B 8 & 14.5 & 17 & 15 & 18 & 16 & 13 & 25.5 & 16 \\
\hline В 9 & 12 & 15.5 & 16.5 & 17 & 16.5 & 12.5 & 25.5 & 16.5 \\
\hline
\end{tabular}

was employed. For strains B 4 and C 6 acid precipitation followed by solid phase extraction (SPE) was used. Resulting active fractions from all of these methods were further purified using RP-HPLC. The purified product from HPLC was analyzed through MALDI-TOF-MS for molecular mass determination.

\section{Thin Layer Chromatography Analysis}

For strain B 8, eight prominent spots were visible under UV having $\mathrm{R}_{\mathrm{f}}$ values of $0.08,0.12,0.21,0.37,0.49,0.53$, and 0.57 . However, only one active fraction was observed upon bioassay with $R_{\mathrm{f}}$ value of 0.49 . The spot was ninhydrin negative indicating the absence of free amino groups and presence of peptide bonds in the compound. A white spot formed with same $R_{\mathrm{f}}$ value when the plate was sprayed with water indicating that the compound is lipophilic. In addition, spots with $R_{\mathrm{f}}$ values of 0.08 and 0.53 could not be stained with ninhydrin while all other spots were ninhydrin positive. For strain B 5, six prominent spots were visible under UV having $R_{f}$ values of $0.1,0.15,0.26,0.37,0.51$ and 0.57 with active fraction having $R_{\mathrm{f}}$ value of 0.37 . The spot was ninhydrin negative and formed a white spot with same $R_{\mathrm{f}}$ value when the plate was sprayed with water indicating that the compound is lipophilic.

\section{Solid Phase Extraction}

Seven fractions were collected by decreasing the polarity with acetonitrile until $100 \%$ and tested for activity. For strain B 4, fractions eluted with 5, 15, 25, and 35\% acetonitrile did not show any activity However, three active fractions were eluted with 50, 75, and $100 \%$ acetonitrile with peak activity at $75 \%$ showing maximum product is eluted when the polarity is decreased until $3 / 4$ to that of start. For strain C 6, maximum activity was observed in the fraction when polarity was decreased to $50 \%$. Both of these fractions were further purified by using RP-HPLC.

\section{Gel Filtration Chromatography}

Gel filtration chromatography was performed by using EconoPack DG 10 column that was equilibrated with $0.01 \mathrm{M}$ Sodium Phosphate buffer, $\mathrm{pH} 7.0$ for B7 and B9. After the sample was applied, 13 fractions were collected each of $1 \mathrm{ml}$ by using same buffer and tested for activity against test strain. The result showed that for both strains sample eluted from the column at two distinct peaks. Initially high molecular weight components were eluted which were above $6 \mathrm{kDa}$ and not of our interest. For strain B7 and B9 maximum activity was found in fraction 9 and 10 respectively which correspond to the molecular weight of about $1.5 \mathrm{kDa}$. These fractions were selected for purification through RP-HPLC. As initial fractions also showed activity, these may represent the aggregated form of antimicrobial compound present in the sample.

\section{Reverse-Phase HPLC}

Fig. (2) show the chromatogram of HPLC purification of samples obtained from TLC. Maximum activity was observed in fraction corresponding to retention time $10 \mathrm{~min}$. for both strains B 8 and B 5 with $15 \%$ recovery and an increase of specific activity to about 8 folds over that of culture supernatant. There was a fair amount of contamination that eluted early and active peaks were observed at retention time 14 and 16 minutes for SPE and gel filtration chromatography respectively. The results revealed that HPLC provided purified samples for molecular mass determination by mass spectrometry.

\section{Molecular Mass Determination}

MALDI-TOF mass spectrometry was used for the accurate determination of molecular masses of purified products from RP-HPLC. The technique has been used as a novel, efficient method for identification and structural 

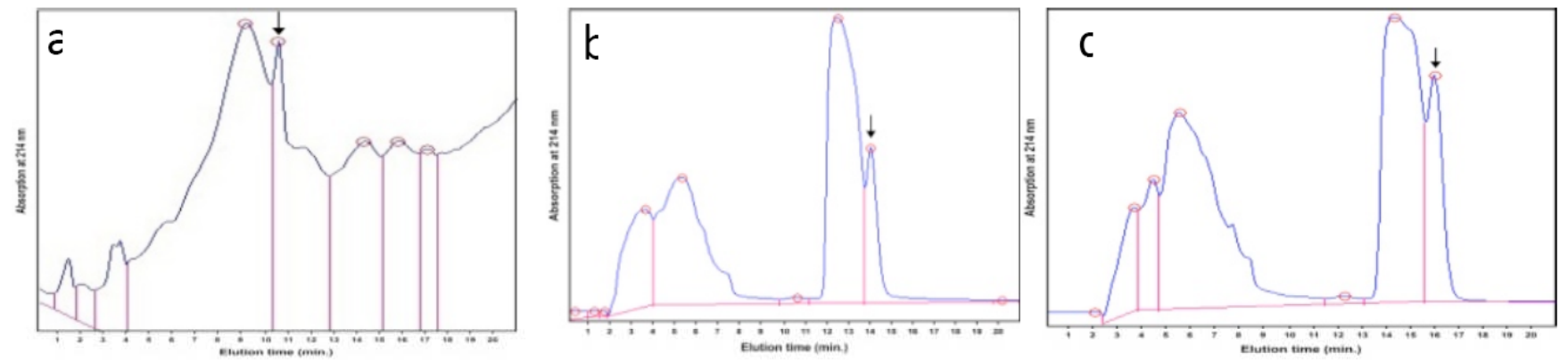

Fig. (2). Reverse phase HPLC chromatogram of antimicrobial substances separated by (a) TLC on a Thermo Hypersil-Keystone ODS column, (b) SPE on a Thermo Hypersil-Keystone ODS column, (c) gel filtration chromatography.

characterization of peptides and proteins with molecular masses ranging from 0.5 to $30 \mathrm{kDa}$. The results obtained for different strains are presented below:

In strain B 8 a cluster of peaks with mass/charge $(\mathrm{m} / \mathrm{z})$ ratios between 1072 and 1098 was observed in linear mode which could be attributed to protonated iturin isoforms and their alkali metal adducts, Fig. (3a). The peak at m/z 1084 was the most intense and corresponds to the mass of $[\mathrm{M}+\mathrm{H}]^{+}$ ion of iturin with a fatty acid chain length of 17 carbon atoms. It showed that $\mathrm{C}_{17}$ iturin like compound is produced by strain B 8 .

In strain $\mathrm{C} 6$ a peak cluster was observed in linear mode with $\mathrm{m} / \mathrm{z}$ ratios between 1012 and 1056 which could be ascribed to protonated surfactin isoforms and their alkali derivatives, Fig. (3b). An intense peak at m/z 1022 matches to the mass of $[\mathrm{M}+\mathrm{H}]^{+}$ion of surfactin with 14 carbon atoms fatty acid chain indicating that $\mathrm{C}_{14}$ surfactin like compound is produced by strain $\mathrm{C} 6$.

In strain B 5 the linear mode, we observed two clusters of peaks with different mass/charge $(\mathrm{m} / \mathrm{z})$ ratios for purified product. One cluster was observed with $\mathrm{m} / \mathrm{z}$ ratios between 976 and 998 which may be regarded as surfactin isoforms. The peak with a $\mathrm{m} / \mathrm{z}$ ratio 994 was the most intense and corresponds to the mass of $[\mathrm{M}+\mathrm{H}]^{+}$ion of surfactin with a fatty acid chain length of 13 carbon atoms. Other cluster was detected with $\mathrm{m} / \mathrm{z}$ ratios between 1088 and 1096, which could be attributed to protonated iturin isoforms. Mass spectrometric analysis revealed that both surfactin and iturin like compounds are produced by strain B 5, Fig. (3c).

In strain B 9 a cluster of peaks with $\mathrm{m} / \mathrm{z}$ ratios between 1022 and 1059 was observed in linear mode which could be attributed to protonated surfactin isoforms and their alkali metal adducts, Fig. (3d). The peak at m/z 1036 was the most intense and corresponds to the mass of $[\mathrm{M}+\mathrm{H}]^{+}$ion of surfactin with a fatty acid chain length of 15 carbon atoms.

In strain B 4 in the linear mode, a cluster of peaks with $\mathrm{m} / \mathrm{z}$ ratios between 1044 and 1112 was observed which could be credited to protonated iturin isoforms and their alkali metal derivatives, Fig. (3e). In the peak cluster the peak with $\mathrm{m} / \mathrm{z}$ of 1070 was most intense and matches to the mass of $[\mathrm{M}+\mathrm{H}]^{+}$ion of iturin with a fatty acid chain length of 16 carbon atoms. This indicated that $\mathrm{C}_{16}$ iturin like compound is produced by strain B 4 .

In strain B 29 in the linear mode, we observed a cluster of peaks with $\mathrm{m} / \mathrm{z}$ ratios between 1036 and 1064 which could be ascribed to protonated surfactin isoforms and their alkali metal adducts, Fig. (3f). In peak cluster an intense peak at $\mathrm{m} / \mathrm{z} 1036$. This peak matches to the mass of $[\mathrm{M}+\mathrm{H}]^{+}$ion of surfactin with 15 carbon atoms fatty acid chain indicating that $\mathrm{C}_{15}$ surfactin like compound is produced by strain B 29 .

\section{Subtilosin Gene}

sbo and its flanking region were detected from the environmental Bacillus strain. Results are shown in Fig. (4) and summarized in Table $\mathbf{5}$ in which all of strains screened were secured sbo class I. Nucleotide sequences were edited manually using Chromas software (http://www.technelsysiu. com.au/chromas.html). PCR sequences were identified using the basic local alignment search tool and GenBank nucleotide data bank from the National Center for Biotechnology Information, Bethesda, MD, USA (http://www.ncbi.nlm.nih.gov). sboX, encoded a bacteriocinlike product, a new gene with an unknown function, in strain 168 [19], which resides in an open reading frame overlapping the coding region of sbo. While the expression of $s b o X$ would result in a 22 -amino-acid curtailed peptide in W23- like strains compared to the peptide produced by 168 like strains, which makes it unlikely that SboX is produced by W23-like strains. However, a correlation between sbo gene and subtilosin production was not established probably due to influence of sboX 186 variation. Hence, this study provided additional strains to support the idea of subtilosin gene predominance amongst Bacillus strains isolated from environment and to report different species containing homologous genes. This is the first report of the detection of subtilosin production by B. amyloliquefaciens based on PCR screening. Further, research must be direct to utilize the $s b o$ genes as a means of identifying different Bacillus species that produce subtilosin.

\section{Phylogenetic Analysis}

Amplified PCR products were sequenced using an ABI Prism dye terminator cycle sequencing ready reaction kit and an ABI PRISM 377 DNA sequencer (Applied Biosystems). Analyses of DNA sequences were performed by using Prochromas version software (Oxford Molecular, UK). The sequences obtained were submitted to GenBank at National Centre of Biotechnology and Information to obtain accession numbers (Table 5). Sequences of sbo for both Bacillus subtilis 168 and Bacillus subtilis ATCC 6633 were used as positive control representing the two classes/ subsp. subtilis (class I) and spizizenii (class II) respectively. These 

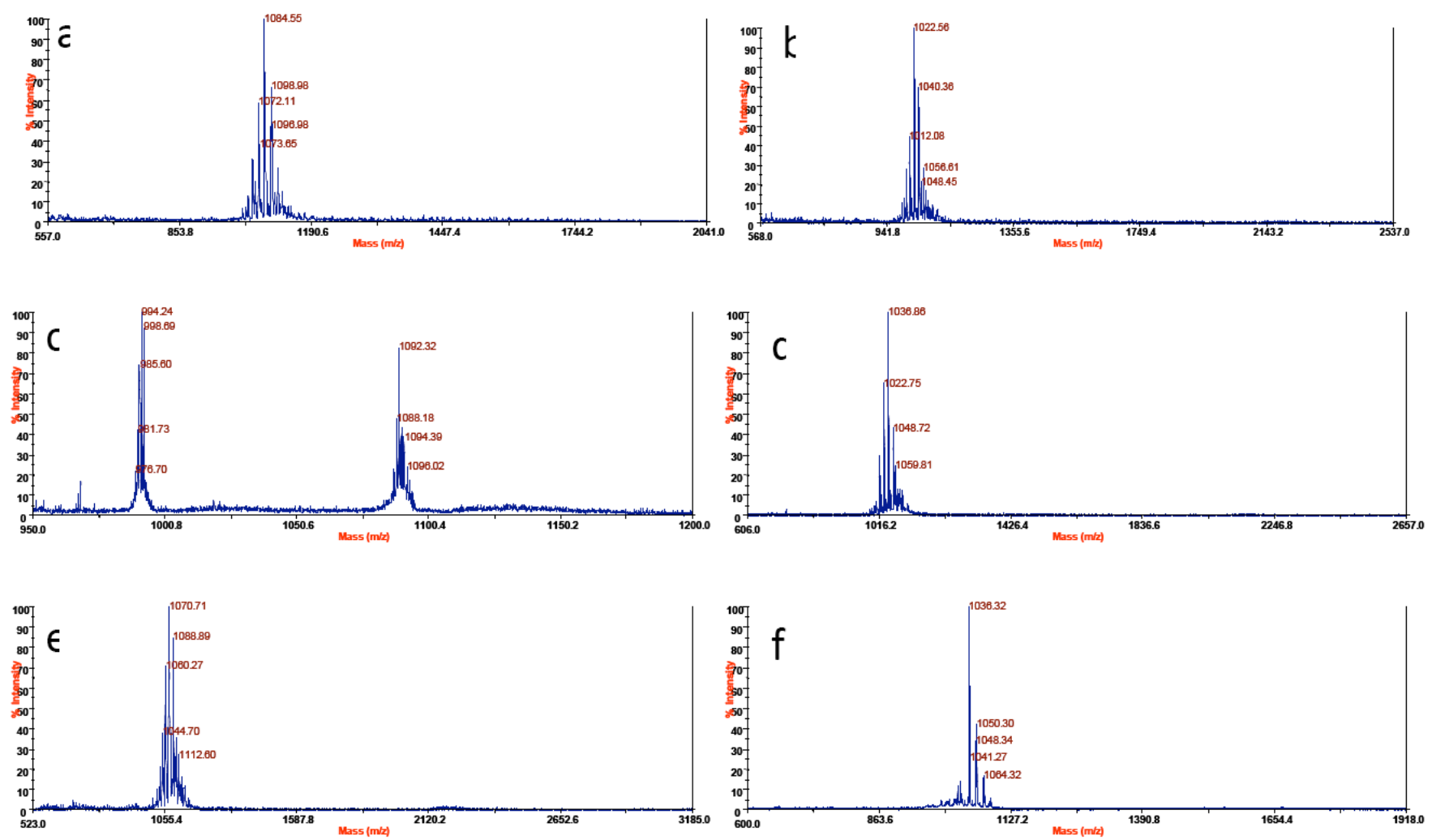

Fig. (3). MALDI-TOF mass spectrometric analysis of (a) iturin like compounds produced by strain B 8 detected in the range from m/z 1072 and 1098, (b) surfactin like compounds produced by strain C 6 detected in the range from m/z 1012 and 1056, (c) surfactin and iturin like compounds produced by strain B 5 detected in the range from m/z 976-998 and 1088-1096 respectively, (d) surfactin like compounds produced by strain B 9 detected in the range from $\mathrm{m} / \mathrm{z} 1022$ and 1059, (e) iturin like compounds produced by strain B4 detected in the range from m/z 1044 and 1112, (f) surfactin like compounds produced by strain B 29 detected in the range from m/z 1036 and 1064.

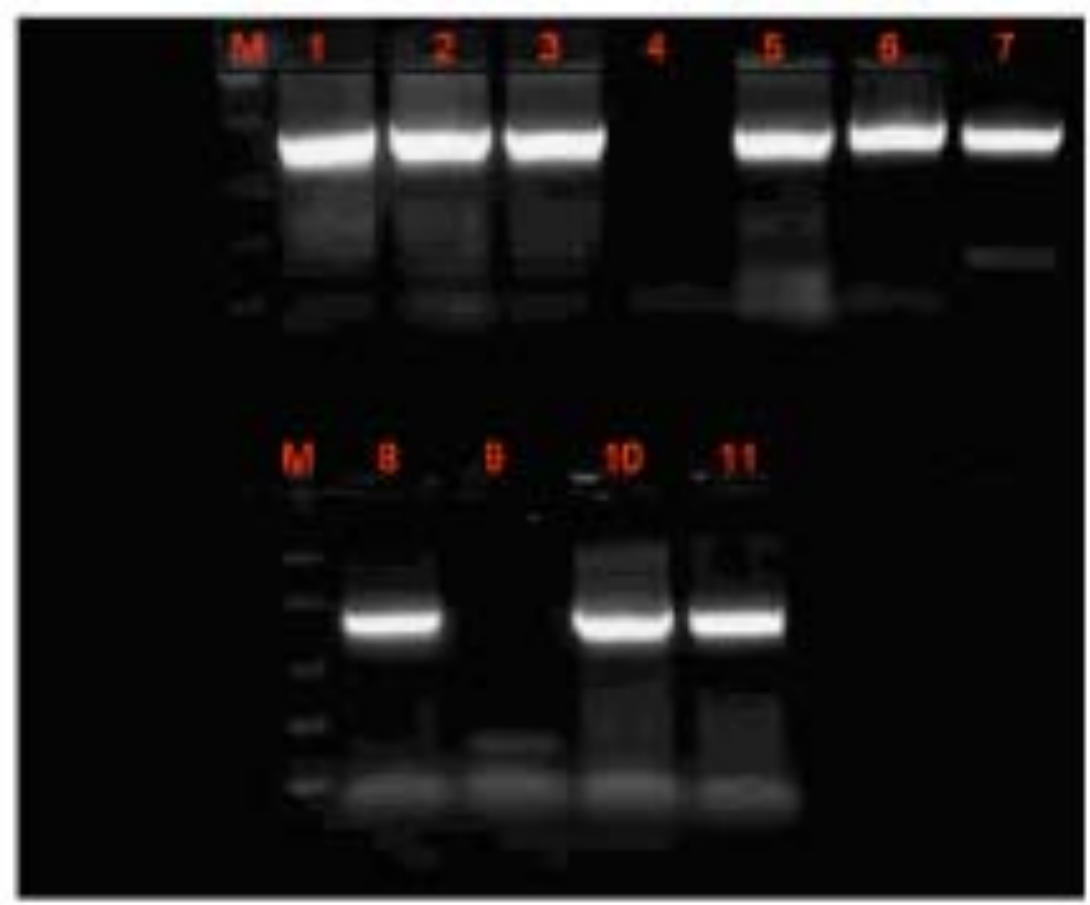

Fig. (4). Positive and negative amplification of sbo-alb region. M: Marker, 1: B4 2: A15, 3: B8, 4: B30, 5: C6, 6: B7, 7: B29, M: Marker, 8: B71, 9: B34, 10: B9. 
Table 5. Summary of the sbo Screened Strains for and Type of Class

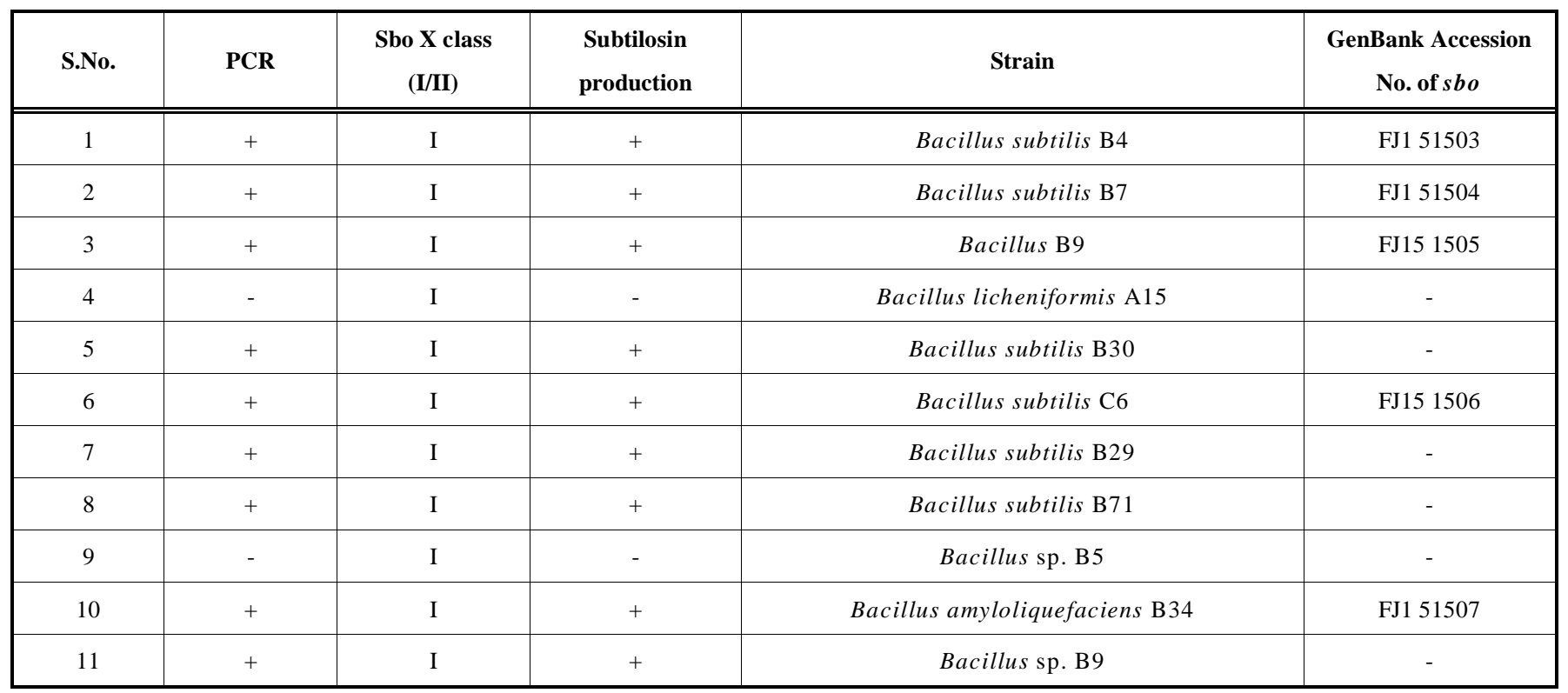

sequences are available from NCBI web site and can be retrieve using search tools or accession numbers. Sequences were analyzed and phylogenetic analyses revealed both classes. All the environmental isolates that produced subtilosin belong to class I, Fig. (5). Multiple sequence alignment of sbo and its flanking region for the strains is given at this thesis in supplemental material.

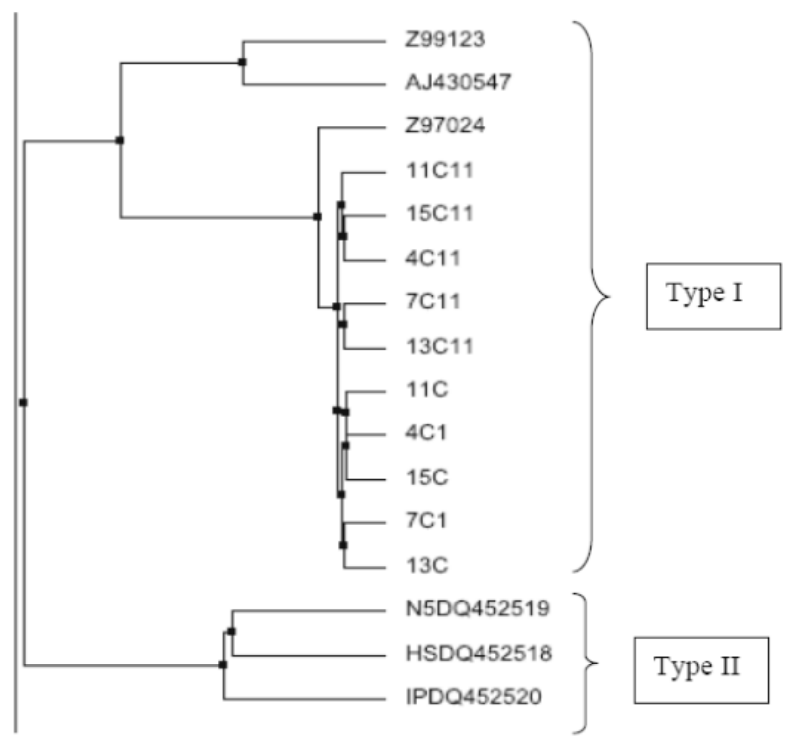

Fig. (5). Phylogenetic diversity of isolated strains using multiple sequence alignments of sequences sbo and flanking region. GenBank accession no. Z99123, AJ430547, Z96024, DQ452519, DQ452518 and DQ452520 belong to strains of corresponding class. 11C11:(B9), 15C11:(B34), 4C11:(B71), 7C11:(B29), 13C11:(B9), 11C:(B5), 4C1:(B30), 15C1:(A15), 7C1:(B7), 13C:(B4).

\section{ACKNOWLEDGEMENTS}

HEC provided grant for visit of Mr. Al-Ajlani to Germany in University of Göttingen to Dr. Laatsch laboratory. Prof. Dr. D. Garozzo, Italy, Prof Dr. H. Laatsch, Prof. Dr. M. Marahiel, Germany are acknowledged for their help in MALDI-TOF analysis.

\section{ABBREVIATIONS}

$\mathrm{AEB}=$ Antimicrobial Exhibiting Bacteria

BHI $=$ Brain-Heart Infusion

HPLC = High Performance Liquid Chromatogrophy

RP-HPLC $=$ Reverse Phase-High Performance Liquid Chromatogrophy

SPE $\quad=$ Solid Phase Extraction

TLC $=$ Thin Layer Chromatogrophy

ZOI = Zone Of Inhibition

\section{REFRENCES}

[1] Schmidt, F. R. The challenge of multidrug resistance: actual strategies in the development of novel antibacterials. Appl. Microbiol. Biotechnol., 2004, 63, 335-343.

[2] Coates, A.; Hu Y.; Bax R.; Page C. The future challenges facing the development of new antimicrobial drugs. Nat. Rev. Drug Discov., 2002, 11, 895-910.

[3] Stachelhaus, T.; Schneider A.; Marahiel M. A. Rational design of peptide antibiotics by targeted replacement of bacterial and fungal domains. Science, 1995, 269, 69-72.

[4] Drablos, F.; Nicholson D. G.; Ronning M. EXAFS study of zinc coordination in bacitracin A. Biochim. Biophys. Acta, 1999, 1431, 433-442.

[5] Katz, E.; Demain A. L. The peptide antibiotics of Bacillus: Chemistry, biogenesis, and possible functions. Bacteriol. Rev., 1977, 41, 449-474

[6] Milner, J. L.; Raffel S. J.; Lethbridge B. J.; Handelsman J. Culture conditions that influence accumulation of zwittermicin A by Bacillus cereus UW85. Appl. Microbiol. Biotechnol., 1995, 43, 685-691.

[7] Steller, S.; Vollenbroich D.; Leenders F.; Stein T.; Conrad B.; Hofemeister J.; Jacques P.; Thonart P.; Vater J. Structural and functional organization of the fengycin synthetase multienzyme system from Bacillus subtilis b213 and A1/3. Chem. Biol., 1999, 6, $31-41$. 
[8] Galvez, A.; Maqueda M.; Cordovilla P.; Martinezbueno M.; Lebbadi M.; Valdivia E. Characterization and biological activity against Naegleria fowleri of amoebicins produced by Bacillus licheniformis D-13. Antimicrob. Agents Chemother., 1994, 38, 1314-1319.

[9] Peypoux, F.; Bonmatin J. M.; Wallach J. Recent trends in the biochemistry of surfactin. Appl. Microbiol. Biotechnol., 1999, 51, 553-563.

[10] Kowall, M.; Vater J.; Kluge B.; Stein T.; Franke P.; Ziessow D. Separation and characterization of surfactin isoforms produced by Bacillus subtilis OKB 105. J. Colloid. Interface Sci., 1998, 204, 18 .

[11] Maget-Dana, R.; Peypoux F. Iturins, a special class of poreforming lipopeptides: biological and physicochemical properties. Toxicology, 1994, 87, 151-174.

[12] Vanittanakom, N.; Loeffler W.; Koch U.; Jung G. Fengycin - a novel antifungal lipopeptide antibiotic produced by Bacillussubtilis F-29-3. J. Antibiot., 1986, 39, 888-901.

[13] Tsuge, K.; Ano T.; Shoda M. Characterization of Bacillus subtilis yb8, coproducer of lipopeptides surfactin and plipastatin B1. J. Gen. Appl. Microbiol., 1995, 41, 541-545.

[14] Mukherjee, S.; Das P.; Sen R. Towards commercial production of microbial surfactants. Trends Biotechnol., 2006, 24, 509-515.

[15] Babasaki, K.; Takao T.; Shimonishi Y.; Kurahashi K. Subtilosin A, a new antibiotic peptide produced by Bacillus subtilis 168: isolation, structural analysis, and biogenesis. J. Biochem., 1985, 98, 585-603.

[16] Stein, T.; Dusterhus S.; Stroh A.; Entian K. D. Subtilosin production by two Bacillus subtilis subspecies and variance of the sbo-alb cluster. Appl. Environ. Microbiol., 2004, 70, 2349-2353.

[17] Zheng, G.; Yan L. Z.; Vederas J. C.; Zuber P. Genes of the sbo-alb locus of Bacillus subtilis are required for production of the antilisterial bacteriocin subtilosin. J. Bacteriol., 1999, 181, 73467355 .
[18] Shelburne, C. E.; An F. Y.; Dholpe V.; Ramamoorthy A.; Lopatin D. E.; Lantz M. S. The spectrum of antimicrobial activity of the bacteriocin subtilosin A. J. Antimicrob. Chemother., 2007, 59: 297-300.

[19] Zheng, G.; Hehn R.; Zuber P.; Mutational analysis of the sbo-alb locus of Bacillus subtilis: identification of genes required for subtilosin production and immunity. J. Bacteriol., 2000, 182, 32663273.

[20] Gerhardt, P. Methods for General and Molecular Bacteriology. Washington, D.C.: American Society for Microbiology, 1994.

[21] Sambrook, J.; Russell D. W. Molecular Cloning a Laboratory Manual. Cold Spring Harbor Laboratory Press, Cold Spring Harbor (N.Y.) 2001, Vol. 3.

[22] Sneath, P. H. A. In Bergey's Manual of Systematic Bacteriology Bergey, D.H.; Sneath, P.H.A.; Holt, J.G.; Eds. Williams \& Wilkins, Baltimore 1986, Vol. 2, 1104-1139.

[23] Hasnain, S.; Thomas C. M. Two related rolling circle replication plasmids from salt-tolerant bacteria. Plasmid, 1996, 36, 191-199.

[24] Johnson, J. L. Similarity analysis of rRNAs. In Methods for General and Molecular Bacteriology. Gerhardt P, Ed. Washington, D.C.: American Society for Microbiology, 1994; pp. 683-700.

[25] Pinchuk, I. V.; Bressollier P.; Verneuil, B.; Fenet, B.; Sorokulova, I.B.; Mégraud, F.; Urdaci, M.C. In vitro anti-Helicobacter pylori activity of the probiotic strain Bacillus subtilis 3 is due to secretion of antibiotics. Antimicrob Agents Chemother., 2001, 45, 31563161 .

[26] Tagg, J. R.; McGiven A. R. Assay system for bacteriocins. Appl. Microbiol., 1971, 21, 943.

[27] Laatsch, H. AntiBase A data base for rapid structural determination of microbial natural products, 2008 and annual updates. Chemical Concepts. Weinheim, Germany: http://wwwuser.gwdg.de/ ucoc/ laatsch/AntiBase.htm, 2008.

(C) Al-Ajlani and Hasnain; Licensee Bentham Open.

This is an open access article licensed under the terms of the Creative Commons Attribution Non-Commercial License (http://creativecommons.org/licenses/by-nc/3.0/) which permits unrestricted, non-commercial use, distribution and reproduction in any medium, provided the work is properly cited. 